\title{
New Medical Therapies for The Treatment of Myelomeningocele
}

ISSN: 2578-0379

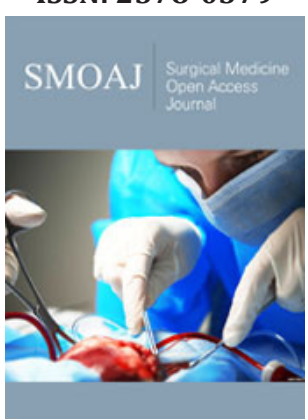

*Corresponding author: Aamir Jalal Al Mosawi, Advisor in Pediatrics and Pediatric Psychiatry, Children Teaching Hospital of Baghdad Medical City, Head, Iraq Headquarter of Copernicus Scientists International Panel, Baghdad, Iraq

Submission: 侮 July 08, 2019

Published: 漹July 22, 2019

Volume 2 - Issue 4

How to cite this article: Aamir Jalal Al Mosawi.New Medical Therapies for The Treatment of Myelomeningocele. Surg Med Open Acc J.2(5). SMOAJ.000549.2019. DOI: 10.31031/SMOAJ.2019.02.000549.

Copyright@ Aamir Jalal Al Mosawi, This article is distributed under the terms of the Creative Commons Attribution 4.0 International License, which permits unrestricted use and redistribution provided that the original author and source are credited.

\section{Aamir Jalal Al Mosawi ${ }^{1,2 *}$}

${ }^{1}$ Advisor in Pediatrics and Pediatric Psychiatry, Children Teaching Hospital of Baghdad Medical City

${ }^{2}$ Head, Iraq Headquarter of Copernicus Scientists International Panel, Baghdad, Iraq

\begin{abstract}
Background: There is no curative or satisfactory effective therapy for the nervous tissue damage associated with myelomeningocele which generally results in a serious disability. The aim of this paper is to describe retrospectively the treatment of four patients with myelomeningocele, three of them were treated with new therapies.
\end{abstract}

Patients and methods: During one-year period from June,2018 to June 2019, four patients with myelomeningocele were observed. Three of the patients were referred for us for treatment and received new therapies aiming at treating the nervous tissue damage associated with myelomeningocele and improving the associated neurological dysfunction. The fourth observed patient was treated by other physicians mainly with physiotherapy and received no specific medical therapy. All the patients had hydrocephalus of variable severity and three of them have already been treated with a ventriculo-peritoneal shunt. Parenteral cerebrolysin was used in three patients with the aim of regenerating the spinal cord cells. Nandrolone decanoate was used in one patient with aim of strengthening muscles of legs.

Result: Treatment of the three patients resulted in a significant improvement that has never been reported before with this condition, and without the occurrence of any side effects. The fourth patients who was not treated by us didn't show any improvement.

Conclusion: The use of new therapies for the treatment of myelomeningocele was found to be very useful and without the occurrence of any side effects. Study of the use of these therapies in a larger number of patients is recommended.

Keywords: Myelomeningocele; Treatment; Cerebrolysin; Nandrolone; Physiotherapy

\section{Introduction}

Spina bifida is a congenital abnormality associated with a defect in the bones and membranes surrounding the spinal cord. The most common site of the abnormality is the lower back. Myelomeningocele which is also called meningomyelocele is the most severe type and causes weakness and impairs the ability to walk. A myelomeningocele may also cause problems with bladder or bowel control, and it may be associated with hydrocephalus. In myelomeningocele, the defect in the vertebral column allows the spinal cord to herniate through an opening, and the meningeal membranes that cover the spinal cord protrude through the opening and form a sac enclosing the spinal elements (meninges, cerebrospinal fluid, and parts of the spinal cord and nerve roots). There is no curative or satisfactory effective therapy for the nervous tissue damage associated with myelomeningocele which generally results in a serious disability except in the less severe forms. Standard treatment of myelomeningocele is surgical closure which aims at preventing more damage of the nervous tissue. The patients may also need a shunt for hydrocephalus. A tethered spinal cord can sometimes be surgically repaired. Patients with myelomeningocele may need devices to aid with movement such as crutches or wheelchairs. Urinary catheterization sometimes is needed [1-4].

The aim of this paper is to describe retrospectively the treatment of four patients with myelomeningocele, three of them were treated with new therapies. Treatment protocol for this research was approved by the scientific committee of Iraq headquarter of Copernicus Scientists International Panel and conform to the provisions laid out in the Declaration of Helsinki (as revised in Edinburgh 2000). 


\section{Patients and Methods}

During one-year period from June 2018 to June 2019, four patients with myelomeningocele were observed. Three of the patients were referred for us for treatment and received new therapies aiming at treating the nervous tissue damage associated with myelomeningocele and improving the associated neurological dysfunction. The fourth observed patient was treated by other physicians mainly with physiotherapy and received no specific medical therapy. All the patients had hydrocephalus of variable severity and three of them have already been treated with a ventriculo-peritoneal shunt. Parenteral cerebrolysin was used in three patients with the aim of regenerating the spinal cord cells. Nandrolone decanoate was used in one patient with aim of strengthening muscles of legs.

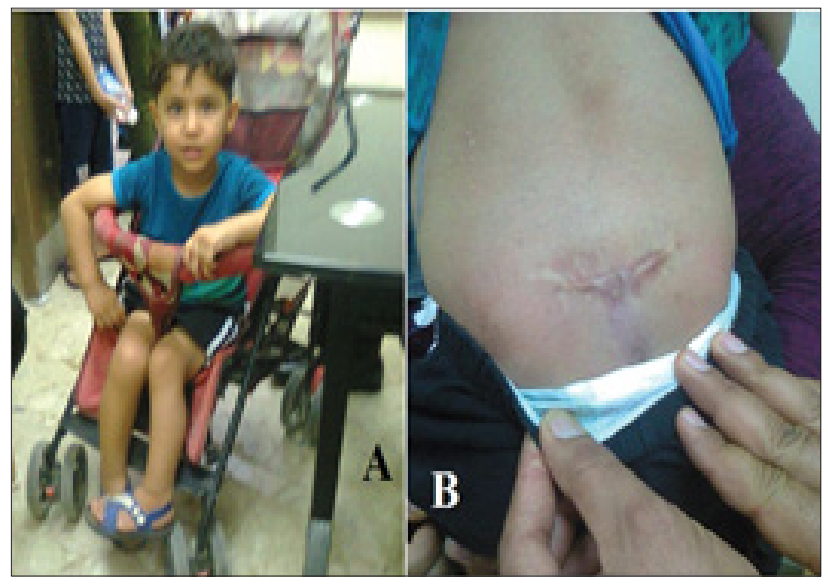

Figure 1: The first patient

(A) He had wasting of the legs and deformity of the feet and needed a wheelchair.

(B) The site of operation for the myelomeningocele.

The first patient was born on the fifth of June 2015. At birth the child had hydrocephalus and myelomeningocele that were operated early during the first month of life. The myelomeningocele was operated on the sixteenth of June, and a ventriculo-peritoneal shunt for hydrocephalus was performed about two weeks later. The boy was first seen at the pediatric neuropsychiatry clinic at the Children Teaching Hospital of Baghdad Medical City during June 2018 at the age of three years. His lower limbs were flaccid (limp) with no sensations in the lower limbs and no spontaneous movement. He also had poor speech development and poor development of fine motor skills as he was unable to copy a line, but he could scribble. The boy had wasting of the legs and deformity of the feet and needed a wheelchair Figure $1 \mathrm{~A} \& 1 \mathrm{~B}$ shows the site of operation for the myelomeningocele. CT- scan of the lumber spine performed on 25th of April, 2018 showed: 1-A bony defect involving the spinous processes and lamina of L5 and the upper sacral vertebrae with herniation of thecal sac measured about (26X24X22mm) containing fluid density 19 HU.2-Mild right sided scoliosis of the lumber spine with diffuse decrease of bone density and atrophy of gluteal compartment with fat replacement. 3-Mild displacement of the femoral head in relation to the acetabulum.
4-Ventriculo-peritoneal shunt was seen in the abdominal cavity. MRI of the lumbo-sacral spine performed on the $6^{\text {th }}$ showed a well defied cystic lesion measuring $2.3 \mathrm{X} 1.7 \mathrm{~cm}$ posterior to $\mathrm{S} 1$ and S2 vertebral bodies.

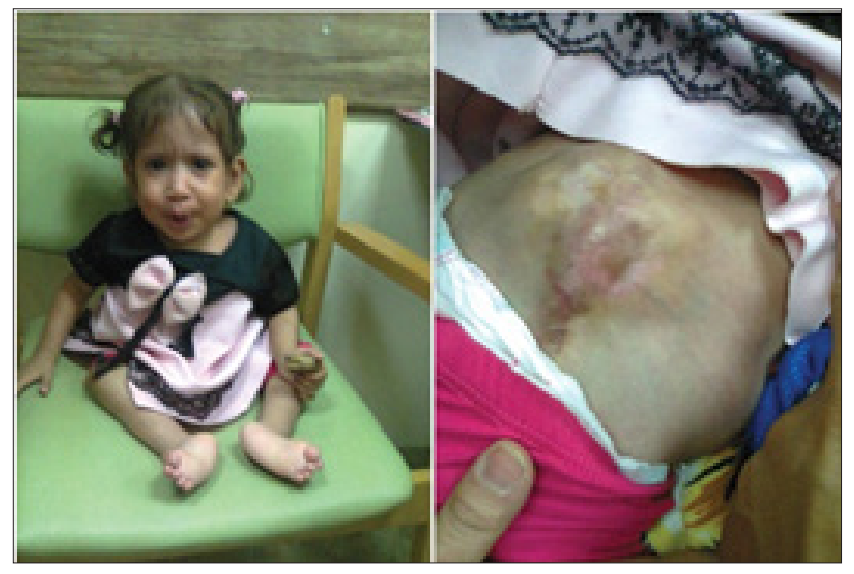

Figure 2: The second patient

(A) The girls' legs showed wasting and she had deformity of the feet.

(B) The site of operation for the myelomeningocele.

The second patient was a girl with hydrocephalus and myelomeningocele who was seen at the pediatric neuropsychiatry clinic at the Children Teaching Hospital of Baghdad Medical City during June 2018 at about the age of two and half years. She had an operation for myelomeningocele at the age on one week, and ventriculo-peritoneal shunt was performed at the age of one month. At the age of five months, nerve conduction study showed severe motor deficit of both lower limbs. Her lower limbs were flaccid (limp) with no sensations in the lower limbs and no spontaneous movement. She also had poor speech development. Her legs showed wasting and she had deformity of the feet Figure 2A \& $2 B$ shows the site of operation for the myelomeningocele. The mother brought the child to the hospital because of constipation and abdominal distention, and she has already been told that there is no therapy for the neurological deficit. Serum potassium and electrolytes were normal. The constipation was treated successfully with oral domperidone (Motilium) and glycerin suppositories. The girl received a course of intravenous cerebrolysin consisting of 10 one ml ampoules given daily as muscle wasting made intramuscular injections difficult.

The third patient was a girl who had small myelomeningocele and mild dilation of the lateral ventricles (seen on CT-scan performed at the age of two years), but neurosurgeons told the parents that she did not need any surgery. She was referred during May 2019 at about the age of six years because of slowness and difficulty in walking, and incontinence. She had squint and refractive error and was wearing glasses (Figure 3A). She had slow abnormal gait, and a small myelomeningocele was preset at her lower back (Figure 3B). MRI of lumbosacral spine performed at the age of five tears showed: Posterior defect of $22 \mathrm{~mm}$ with small myelomeningocele (12 X7X19) $\mathrm{mm}$. Lower meningeal cyst. Evidence of cord tethering with conus 
ends at the level of L3-L4. Previous ultrasound studies suggested bilateral progressive hydronephrosis with the more recent studies showing severe bilateral hydronephrosis with bilaterally dilated and tortuous upper ureters. The bladder wall was trabeculated. Prevoiding urine bladder volume was $46.2 \mathrm{ml}$, while post-voiding urine bladder volume was $45.7 \mathrm{ml}$. The findings of voiding cytometry performed on the 23rd of July 2017 suggested the diagnosis of detrusor over activity with compliance and leak of urine leading to urge incontinence. Before referral a urologist treated her on two occasions with cystoscopy injection of Botox, but without any benefit. The girl was treated with 20 intramuscular injections of $5 \mathrm{ml}$ cerebrolysin over one month. The first 10 injections were given daily for 10 days, the second 10 injections were given every other day. She also received oral alphazocin (Xatral-XL) 10mg daily as a single dose at night as treatment for her neurogenic bladder.

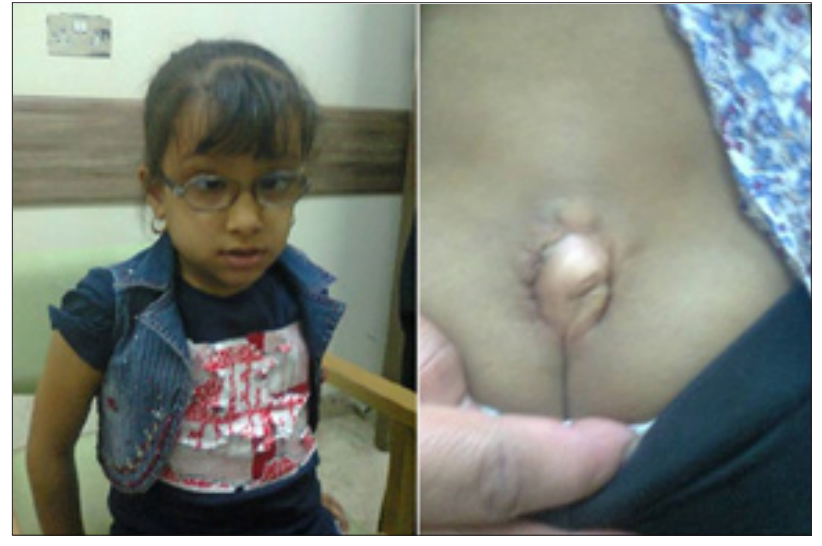

Figure 3: The third patient

(A) She had squint and refractive error and was wearing glasses

(B) She had slow abnormal gait, and myelomeningocele was preset at her lower back.

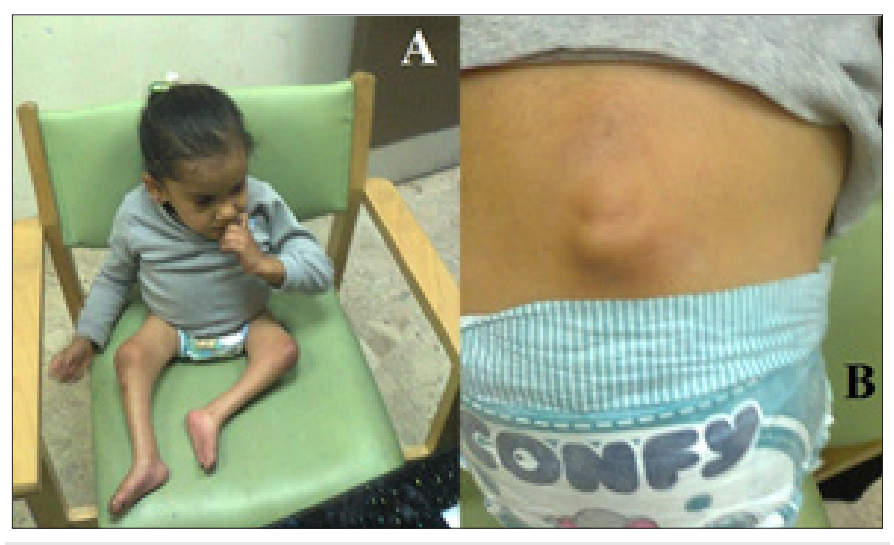

Figure 4: The fourth patient

(A) The girl was first at about the age of seven years while she was under the care of other physicians.

(B) She had a remnant of the myelomeningocele at her back.

The fourth patient (Figure 4A) was first seen during June 2018 at about the age of seven years while she was under the care of other physicians. Her lower limbs were flaccid (limp) with no sensations in the lower limbs, and no spontaneous movement. Her hydrocephalus and myelomeningocele were operated early during life. However, there was a remnant of the myelomeningocele could be seen at her lower back (Figure 4B).

\section{Result}

The treatment of the three patients resulted in a significant improvement that has never been reported before with this condition. The fourth patients who was not treated by us didn't show any improvement (Table 1).

Table 1: Summarize the treatment of the first patient.

\begin{tabular}{|c|}
$\begin{array}{c}\text { Treatment Given to The First Patient } \\
\text { The First Course of Treatment }\end{array}$ \\
\hline $\begin{array}{c}\text { A-Intramuscular cerebrolysin: } 15 \text { one ml ampoules given over one month. The first five ampoules were given daily, and the remaining } 10 \text { were given } \\
\text { every other day. }\end{array}$ \\
\hline $\begin{array}{c}\text { B-Single injection of intramuscular nandrolone decanoate } 25 \mathrm{mg} \text { with amino acid supplementation were given after the first course of cerebrolysin } \\
\text { treatment. }\end{array}$ \\
\hline A-Intramuscular cerebrolysin: 3ml given every third day over one month. \\
\hline B- A second injection of intramuscular nandrolone decanoate $25 \mathrm{mg}$ intramuscular was given while amino acid supplementation was continued. \\
\hline The Third Course of Treatment \\
\hline Intramuscular cerebrolysin: 4ml given every third day over one month. \\
\hline The Fourth Course of Treatment \\
\hline Intramuscular cerebrolysin: $5 \mathrm{ml}$ given every third day over one month. \\
\hline
\end{tabular}

\section{The first patient}

After the first five injections of cerebrolysin, he experienced marked improvement in sensation, and some improvement in the tone of the lower limbs, and he was showing spontaneous little movements of the lower limbs. After the first course of treatment, about ten days after nandrolone injection, he showed marked improvement in muscle tone and was able to lift his feet up for more than $1 \mathrm{~cm}$. He showed obvious improvement in his feet deformity and was able to sit on a chair unaided (Figure 5A), and he was also able to bear weight while holding furniture (Figure 5B). After 
the second course of treatment significant improvements were observed:1-Improvement in muscle mass and strength. 2-The child was able to sit comfortably on the chair, and no muscle atrophyof the lower limbs was obvious (Figure 6A). 3-The child was able to lift his legs while sitting on the chair more than $5 \mathrm{~cm}$ (Figure 6B,6C). 4-The child had normal sensation in the lower limbs. 5-The child showed improvement in weight bearing when supported by his mother (Figure 6D). 6-The child showed obvious improvement in speech. After the fourth course of treatment, the boy was able stand holding a chair for a long time (Figure 7).

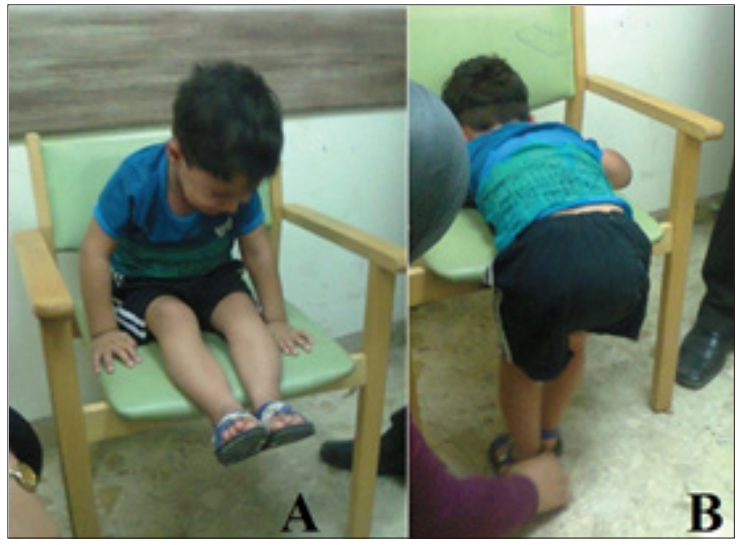

Figure 5: The first patient after the first course of treatment

(A) The boy showed obvious improvement in his feet deformity and was able to sit on a chair unaided.

(B) He was able to bear weight while holding furniture (a chair).

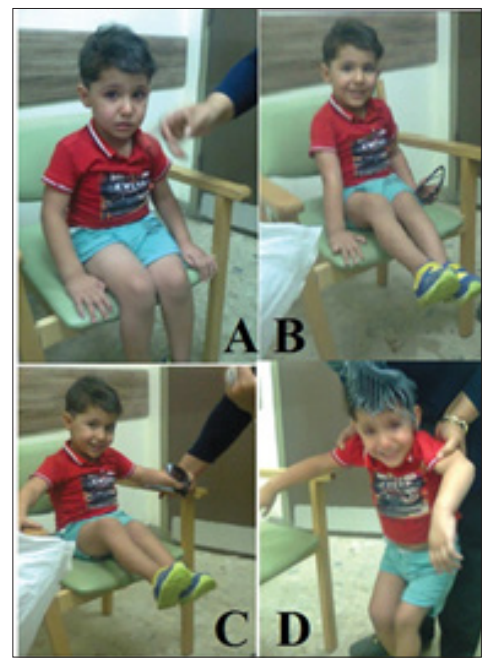

Figure 6: The first patient after the second course of treatment

(A) The child was able to sit comfortably on the chair, and no muscle atrophy of the lower limbs was obvious.

(B) The child was able to lift his legs while sitting on the chair more than $5 \mathrm{~cm}$ and moving them rapidly.

(C) The child was able to lift his legs while sitting on the chair more than $5 \mathrm{~cm}$ and moving them rapidly.

(D) The child showed improvement in weight bearing when supported by his mother.

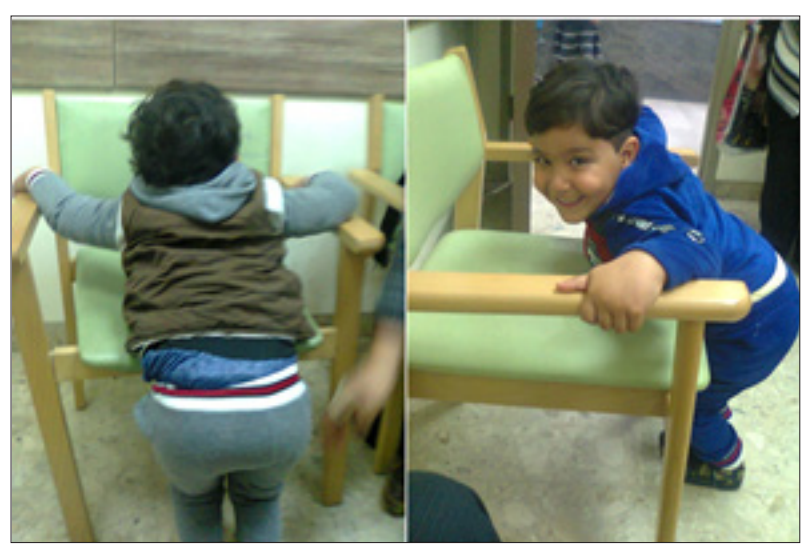

Figure 7: The first patient after the fourth course of treatment, he was able stand holding a chair for a long time.

\section{The second patient}

After treatment, she had normal bowel motion and no abdominal distention. She also showed obvious improvement in sensations in the lower limbs, and spontaneous movement was initiated. The follow-up of the patient was lost most probably because of marital problems.

\section{The third patient}

After treatment she had marked improvement in her gait and incontinence.

\section{The fourth patient}

Over about one year of observation under the care of other physicians offering her only physiotherapy, she didn't show any improvement of any kind.

\section{Discussion}

There is no curative or satisfactory effective therapy for the nervous tissue damage associated with myelomeningocele which generally results in a serious disability except in the less severe forms. In this paper the use of new therapies was found to be very useful and without the occurrence of any side effects.

The use of cerebrolysin was beneficial and safe in the treatment of various childhood neuro-psychiatric disorders including brain atrophy [5], mental retardation [6], developmental and pervasive developmental disorders [7], cerebral palsy [8], and Rett syndrome [9]. Cerebrolysin is a peptidergic medicine which contains mainly biologically active neuro-peptides including brain-derived neurotrophic factor, glial cell line-derived neurotrophic factor, nerve growth factor, and ciliary neurotrophic factor. It has a nerve growth factor like activity on neurons, and growth promoting efficacy in different neuronal populations from peripheral and central nervous system. Cerebrolysin has a direct neurotrophic effect, and obvious neuroprotective properties against many types of lesion in vitro and in vivo. The therapeutic effects of cerebrolysin have been considered to be similar to the pharmacological activities of naturally occurring nerve growth factors [5-9]. 


\section{The neuroreparative effects of cerebrolysin have been attributed to [5-9]:}

Cerebrolysin acts as a neurotrophic and neuroprotective agent. This function may contribute delaying the progression of brain disorders. Inhibition or minimizing cell death rate which is called apoptosis. This function may contribute to improving many brain disorders. Improving synaptic plasticity. Induction of neurogenesis which is a process of development of new nerve cells. Induction of neurogenesis is especially necessary in the hippocampus to enhance the memory formation process. Augmenting the proliferation, differentiation, and migration of adult subventricular zone neural progenitor stem cells that contribute to neurogenesis. Induction of stem-cell proliferation in the brain. Promoting synaptic repair in the region of the hippocampus leading to enhancing overall neurotransmission. Nandrolone decanoate is an anabolic steroid with muscle strengthening effects. A judicious safe use of nandrolone by the experts has been reported in the treatment of various childhood brain atrophy, cerebral palsy, refractory vitamin D-resistant rickets, and achondroplasia $[10,11]$.

\section{Conclusion}

The use of new therapies for the treatment of myelomeningocele was found to be very useful and without the occurrence of any side effects. Study of the use of these therapies in a larger number of patients is recommended.

\section{Acknowledgement}

The author would to express his gratitude for the parents of the patients who accepted publishing his photos.

\section{References}

1. Hodgkinson K (1982) Myelomeningocele: The spina bifida effect. Aust Nurses J 11(9): 39-41.

2. Lapras C, Guilburd JN, Patet JD (1988) Spina bifida aperta: myelomeningocele. Chiari's malformation type II. Neurochirurgie 34 (Suppl 1): 53-58.

3. Pasquariello PS, Sutton LN, Whitehead AS, Mitchell LE, Adzick NS, et al. (2004) Spina bifida. Lancet 364 (9448): 1885-1895.

4. Kondo A, Kamihira O, Ozawa H (2009) Neural tube defects: Prevalence, etiology and prevention. International Journal of Urology 16 (1): 49-57.

5. Al Mosawi AJ (2017) A novel therapeutic approach for the treatment of brain atrophy. LAP Lambert Academic Publishing, Germany.

6. Al Mosawi AJ (2018) A novel therapeutic approach for idiopathic mental retardation. LAP Lambert Academic Publishing, Saarbrücken, Germany.

7. Al Mosawi AJ (2019) The use of cerebrolysin and citicoline in autism and Asperger syndrome. J Bio Innov 8(1): 99-108.

8. Al Mosawi AJ (2019) New Therapies for the Treatment of Spastic Cerebral Palsy. Med J Clin Trials Case Stud 3(2): 000209.

9. Al Mosawi AJ (2019) New therapies for Rett syndrome. J Bio Innov 8(3): 301-307.

10. Al Mosawi AJ (2005) Experience with refractory vitamin D-resistant rickets and non-17 alkyl testosterone derivative anabolic agent. Therapy (Clinical practice) 2(1): 91-94.

11. Al Mosawi AJ (2006) Dramatic effect of non-17 alkyl testosterone derivative anabolic agent on growth in a child with achondroplasia on the short term. Therapy (Clinical practice) 3(5): 605-607. 